\title{
The replacement of the engineer under the new FIDIC Red Book 2017: issues of agency and privity of contract, with a note on Qatar
}

\section{Nisreen Mahasneh}

Faculty of Law, Qatar University, P.O. Box 2713, Doha, Qatar

Email: nmahasneh@qu.edu.qa

\begin{abstract}
New rules have been introduced in the 2017 edition of the FIDIC Red Book, particularly in relation to the replacement of the engineer. Hence, the contractor has now become under a time limit to respond to the relevant notice issued by the employer. Failing to comply with such a time line would have the implication of considering the contractor to be deemed to have accepted such replacement. Furthermore, replacement may occur for reasons attributable to the engineer itself, such as illness, disability or resignation. In which case, the employer must immediately appoint a temporary engineer. Clearly, such an appointment needs to be confirmed by the contractor, if not so approved then the employer must appoint another engineer. Also, the engineer has the right to appoint and/or replace a representative to work on site, without having to obtain the contractor's approval. However, the contractor must seek the engineer's approval when appointing and/or replacing its representative, once the same takes place following the commencement of the contract. All in all, the contractor decision as to the replacement of engineer must always be objective and on merit.
\end{abstract}

Keywords: engineer; employer; contractor; replacement; FIDIC; Red Book 2017; privity of contract; Qatar.

Reference to this paper should be made as follows: Mahasneh, N. (2020) 'The replacement of the engineer under the new FIDIC Red Book 2017: issues of agency and privity of contract, with a note on Qatar', Int. J. Private Law, Vol. 9, No. 4, pp.246-258.

Biographical notes: Nisreen Mahasneh is a Professor in Private Law. Her areas of interest are contracts, tort and international trade. She has published a number of articles and book chapters in Arabic and English at regional and international journals covering various aspects of contracts, Islamic jurisprudence, legal education besides three books on international trade, legal research and writing and finally contract law. She holds an LLB and LLM degrees from the University of Jordan, and $\mathrm{PhD}$ from University of Aberdeen. She worked for 15 years at the Yarmouk University in Jordan, prior to joining Qatar University, in 2016. 


\section{Introduction}

The most recent edition of the 'Conditions of contracts for construction' issued by the International Federation of Consulting Engineers (FIDIC) (2017 Red Book) introduced a number of fundamental changes from the last edition (the 1999 Red Book). This article discusses one of these changes, relating to the rules for replacing the engineer, as provided for mainly in Sub-clause 3.6 of the 2017 Red Book.

The importance of this topic emerges out from the fact that the Red Book is highly used in constructions. Moreover, the engineer plays an instrumental role in the contract, being in direct interaction with both parties (the employer and the contractor). Therefore, any change by the FIDIC to any aspect of his relationship with the parties of the contract is worth analysing. This article tries to answer the following main questions among others:

1 How can one understand the requirement of the contractor's approval as to the replacement of the engineer by the employer, in the light of the principle of privity of contract?

2 What is exactly the legal position of the engineer, when being replaced by the employer?

3 What are the differences between the cases of replacement of the engineer by the employer's sole authority, and the new case introduced by the 2017 edition, where replacement takes place for reasons attributable to the engineer itself?

4 How do the fundamental differences that exist between the FIDIC and domestic law, particularly with regards to the nature and the role of the engineer in construction contract, affect the use of FIDIC books?

All of these issues and other related ones are discussed below.

\section{Replacement of the engineer by the employer}

Considering the fact that the engineer is appointed and paid for by employer ${ }^{1}$, it can then be assumed that the employer has full authority and/or discretion to remove or replace the engineer, a right that derives directly from the contract. Yet, the legal dilemma that arises when replacing the engineer relates to defining the engineer's legal position at replacement: agent, contractor or employee? ${ }^{2}$ Then, to understand whether or not the principle of privity of contract is ignored by replacement procedures.

\subsection{Legal position of the engineer at replacement}

The 2017 Red Book's definition of employer's personnel supports the notion that all people who work for the employer are equal in terms of legal position - all are the employer's personnel, including the engineer. Therefore, the terminology of 'personnel' is broad and covers agents and employees. ${ }^{3}$

Sub-clause 3.2 of the 2017 Red Book provides that engineer is deemed to act for employer. This accords with most, if not all, jurisprudence, which holds that the contract between the employer and the engineer is agential. ${ }^{4}$ However, according to both versions 
of the Red Book (1999 and 2017), the engineer is not always agent who acts for the employer. Both versions use the qualification, 'except as otherwise stated' ${ }^{5}$

Therefore, the engineer wears more than one hat in his relationship with the employer. On the one hand, he is acting for the employer, which makes him an agent; on the other hand, whenever the engineer is using his authorities in settling disputes between the parties (agreement and determination), he must act neutrally in accordance with its vested authorities. ${ }^{6}$ Sub-clause 3.7 (agreement and determination) of the 2017 Red Book expressly provides that the engineer is not acting for the employer in such case. ${ }^{7}$ If the engineer is not an agent in this case, what is his legal position? In answering this question, one may well say that he is a contractor, provides both parties with technical services. To this extent, the engineer becomes independent.

It is worth noting here that the 1999 Red Book used in the context of describing the exercise of engineer's functions (agreement and determination) the terminology of 'fairly'. Hence, the engineer was required to perform its activities in a 'fair' manner. Further, the 'agency' element was not expressly excluded. ${ }^{8}$ It is the author's view that by the introduction of the concept of 'neutrality', the 2017 Red Book clearly eliminates the notion of agency, deciding expressly that determinations and agreements are among the cases 'of otherwise stated in these conditions'. 9 '

Even in the cases where the engineer acts as an agent, such an agency is restricted; for example, he cannot amend the contract or relieve parties from their obligations, and some decisions cannot be taken by the engineer without the employer's consent. ${ }^{10}$

When answering the question as to what is the legal position of the engineer at replacement, it can be concluded that he is being replaced by the employer as an agent, that is because the general rule under the FIDIC is that the engineer is acting for the employer, the exception being where there is an express indication to this under the general conditions. Moreover, under agency contract, principal can remove agent at any time, even if an agent is not at fault or is not in breach of contract ${ }^{11}$, which is the case when the employer uses his sole discretion in replacement. This position is reflected in the 2017 Red Book, which does not mention an engineer's failure to carry out its duties as being a reason for replacing him. What is more, the 2017 Red Book gives the engineer no right to challenge the employer's decision to replace it.

\subsection{Procedures of replacement and privity of contract}

There are some restrictions on the employer's ability to execute such replacement. Here, Sub-clause 3.6 of the 2017 Red Book binds the employer who decides to replace the engineer to notify the contractor of such decision not less than 42 days before the date of replacement and to provide the contractor with the name of the new engineer, address and relevant experience. It is worth noting that this requirement is the same as it was under the 1999 Red Book. ${ }^{12}$

One may say here that the said requirement clashes strongly with the doctrine of privity of contract. ${ }^{13}$ That is to say, as that the contractor is not a party to the contract, concluded between the employer and the engineer, the employer should not then need legally to inform the contractor when it intends to replace the engineer, or indeed to seek its approval.

The 2017 Red Book clashes further with privity of contract, in that it gives the contractor the right to object to replacement. Contractor has 14 days to respond to employer's notice. Where the contractor fails to respond within this period, it is then 
deemed to have approved the new engineer. But where contractor objects within the period, it effectively nullifies the replacement, subject to criterion of reasonableness. By a way of comparison, it is to be noted here that the time limit given to the contractor under Sub-clause 3.6 of the 2017 Red Book has no counterpart under the 1999 version.

However, the mere objection by the contractor is not sufficient; Sub-clause 3.6 sets a criterion for the contractor's objection to the replacement of the engineer by the employer, which is 'reasonableness'. Once the contractor chooses to respond to the employer by sending a notice objecting to the replacement, the employer may accept the objection, and nominate another engineer, but on the other hand, he may insist on the engineer appointed by him as a replacement. In the latter case, a dispute arises, which must be settled in accordance with mechanism agreed in the contract between the employer and the contractor. ${ }^{14}$ The employer can attempt to prove that the contractor's objection was not reasonable. ${ }^{15}$

How, though, can we square the contractor's right to be notified about and to object to the replacement of the engineer in the 2017 Red Book with the requirement that the principal (here, the employer) must have sole authority to remove its agent (here, the engineer)? The answer is essentially one of practicality; the employer's duty to inform the contractor about the appointment of a new engineer is understandable, given that the contractor works closely with the engineer, and takes direct and indirect instructions from him. Furthermore, the contractor who objects to a replacement of the engineer must do so reasonably, and the employer has the right to challenge, meaning that the final decision rests with the employer. In other words, the consent of the contractor is not required, but because of the very special relationship between the contractor and the engineer, and for the best interest of the project, it is better that the contractor has no objection to the new engineer.

To sum up, the said procedures do not necessarily clash with the doctrine of privity of contract, since the final say is the employer's one.

\section{Replacement for reasons attributable to the engineer}

There are some cases in which the engineer cannot perform its duties under the contract; hence, different procedures of replacement are applied here. This section will deal with these two relevant procedures.

\subsection{Engineer's related cases of replacement}

Unlike the 1999 version, the new FIDIC recognises cases where the employer replaces the engineer because of circumstances that relate to the engineer itself. Those cases are: the death of the engineer, illness, disability, or resignation, besides the case where the engineer is an entity which becomes unable or unwilling to carry out its duties under the contract. ${ }^{16}$

The common factor between all the said mentioned cases is that none of them is attributable to the employer; instead they are all engineer-related.

According to the general rules of law, the agency contract terminates on the death of the agent. This is due to the personal nature of this contract. ${ }^{17}$ Also, the agent is entitled to remove itself from the contract. ${ }^{18}$ Moreover, where the agent is unable to perform its 
duties due to illness or disability, the principal has good grounds to replace and/or remove the agent. ${ }^{19}$

Arguably, the employer does not need a legal provision expressly authorising him to replace an engineer in the case of illness and disability, since those two cases are covered by the first paragraph of Sub-clause 3.6, discussed above, where the employer can use his own discretion. However, the importance of including those cases under the last paragraph of Sub-clause 3.6 lies on the procedures that must be followed by the employer, which are different from those when replacement is exercised by the employer under the first paragraph of Sub-clause 3.6. ${ }^{20}$

To illustrate, all of the cases above (death, illness, disability and resignation) constitute emergency cases which the employer has not expected, and for which it has no time to think and then make suitable arrangements. Conversely, the employer can in other cases and for other reasons exercise its authority and make its own discretion/judgement, which is normally based on considerations such as the interest of the project, lack of performance on the engineer's side. When replacement is conducted for reasons that relate to the engineer, the employer is entitled to immediately appoint a new engineer by giving a notice to the contractor with the name, address, relevant experience of the new engineer and reason of replacement. But this appointment is valid immediately, with no time given to the contractor to object, however, it is treated as a temporary appointment, which means that the contractor may accept the new engineer after its appointment, if not a new replacement must be made by the employer and accepted by the contractor.

\subsection{Comparison between the two types of replacement}

The differences between replacement the engineer under the first paragraph of Sub-clause 3.6 (discretion of the employer) and the last paragraph (engineer related reasons) are follows.

First, there are time limits within which the employer can exercise replacement as its sole authority by sending a notice to the contractor. ${ }^{21}$ And such time limits do not exist when replacement is made for a reason attributable to the engineer. This difference is understandable, given the emergency nature of the engineer's related replacement reasons.

The second difference is embodied within the legal consequence of replacement; here temporary replacement under the last paragraph becomes immediately valid, and gets converted to a permanent appointment upon the contractor approval of such temporary engineer. However, replacement under the first paragraph becomes valid only once approved by the contractor. If not so approved, the employer must appoint another engineer and seek another approval of the contractor.

The said rule can be explained and justified on the best interest of the project, as it is vital that the engineer must not depart from the site, whether for short or long time, pending the contractor's approval. Hence, the rule of having a temporary engineer operates to achieve two purposes; on the one hand, it rescues the project from stoppage, thereby protecting the interests of the employer. On the other hand, it preserves the right of the contractor of ultimately approving the new engineer. Indeed, this mechanism may help boost relationship and effective cooperation between the engineer and the contractor.

The third difference between first and last paragraph of Sub-clause 3.6 is that silence of the contractor for 14 days after the employer appoints a replacement using his sole authority, reflects an implied approval by the contractor to the replacement. However, 
there is no such a rule when replacement is conducted for reasons attributable to the engineer. The question being now, what is the legal effect of the contractor's silence in this case? One may well say that the new engineer continues to be temporary, because the contractor has no time limits to approve or disapprove. It was better if the FIDIC provided for a time limit in this case, so that to achieve legal stability for both the temporary engineer and the employer.

Practically, the employer sometimes appoints a temporary engineer only to have more time to find a more qualified one, or until the desired engineer becomes ready and available to start work. The questions that arise here is that: can the employer replace the appointed temporary engineer even before receiving the approval of the contractor on the already appointed temporary engineer? What if the contractor approves the temporary engineer, but the employer still desires to replace him?

To answer these questions, one may well say, the employer should have the right to replace the temporary engineer, because replacement in this case is for his interest in the first place. Yet, a distinction must be made here between two assumptions; the first when the replacement of the temporary engineer is prior to the contractor's approval of the appointment of the said engineer, here, the employer may send a new notice of the replacement, but the new engineer will be deemed a temporary one. The second case is where the contractor approves the temporary engineer, then the employer can only exercise replacement under the first paragraph of Sub-clause 3.6, with the contractor's approval, that is because the engineer is no longer a temporary one.

The common issue between Replacement under the first paragraph and last paragraph of Sub-clause 3.6 is that while the contractor is not a party to the contract between the employer and the engineer, he is entitled to approve the engineer's appointment, and without this approval the appointment of the engineer will not prevail.

It remains that the criteria of reasonable objection by the contractor should be applied to the case of rejecting the appointment of the temporary engineer, which in turn enables the employer to challenge the contractor's objection, and in some cases to impose the engineer against the wishes of the contractor, when the objection of the contractor proved to be unreasonable.

\section{Replacement of representatives}

Under the 2017 Red Book, both the contractor and the engineer can have their representatives, the question here is what are the rules governing replacement of those representatives.

\subsection{Replacement of the contractor's representative}

It is important first to briefly shed some light on the nature of relationship between the contractor and the engineer, so that the engineer's role in appointing and replacing the representative of the contractor is better understood.

In principle, the contractor does not have any right to replace the engineer. The employer, it should be noted, is not obliged to seek his contractor's approval when appointing the engineer in the first place. However, the contractor must approve replacement of the engineer if it takes place after the commencement of works. The 
rationale behind this being that the real work has begun, and the contractor, his representative and assistants are dealing with this engineer, hence, any change in this critical stage would affect the interest of the contractor and that of the project.

The engineer instructs the contractor, contractor's representative and its assistants, all of whom are bound by those engineer's instructions. ${ }^{22}$ What is more, the engineer's representative and assistants are all authorised to instruct the contractor. ${ }^{23}$ The contractor may not object to the engineer's instructions. However, under Sub-clause 3.5 of the 2017 Red Book, the contractor is free to interpret this said instruction, although it must notify the engineer that it is doing so, and the engineer shall have the final word. ${ }^{24}$

Notwithstanding, when the contractor is not satisfied by the engineer's work, the contractor may ask employer to exercise its authority in replacing the engineer. Though, the contractor is not in a position to impose on the employer the exercise of such an authority. ${ }^{25}$

It is worth indicating to Sub-clause 4.3 of the new FIDIC which stipulates that the contractor must appoint a representative ${ }^{26}$, who must be an engineer. The representative acts on the contractor's behalf, and enjoys all authorities, except replacing the contractor's representative.

This representative can be appointed in earlier stages of contracting and be named in the contract, without having to obtain the consent of the engineer. However, if this appointment delays to after contracting, the engineer must approve such an appointment. And the same applies to replacement of contractor's representative.

If the engineer does not give its consent to the appointment or replacement of the contractor's representative, the contractor must then nominate another representative. Yet, if 28 days elapse after submission of the proposed representative whether for appointment or replacement, without any objection from the engineer, the engineer shall then be deemed to have given its consent. It is worth noting here that the period given to the engineer to provide its consent is double than the one given to the contractor to approve replacement of the engineer. What is more, it is to be noticed that while the engineer is required to approve both the appointment, or replacement of the representative, the contractor's approval is required only for the replacement of engineer. No approval is to be sought from the contractor for appointing the engineer in the first place. Most importantly, the engineer's objection to the appointment or replacement of the contractor's representative is not subject to the criterion of reasonableness, in contrast with the case of the contractor's objection to the replacement of the engineer.

Similarly, the same rules that apply in the case of (death, illness, disability and resignation) of the engineer apply also to the contractor's representative. To illustrate, a temporary representative needs to be immediately appointed by the contractor, until the engineer gives his consent, and if not so approved, a new representative has then to be appointed and approved by the engineer. ${ }^{27}$

\subsection{Replacement of the engineer's representative}

One of the new rules in the 2017 Red Book relates to the engineer's representative; the engineer has the right to appoint a representative to wholly work in the site. ${ }^{28}$ All rules that apply to the original engineer apply equally to the engineer's representative. However, the engineer can appoint and replace his representative without the contractor's approval. The only interference of the contractor is where the representative cannot be at the site all times, in which case the engineer must appoint a competent replacement of the 
representative and notify the contractor to this effect. The contractor is not entitled to object or approve; it is only that he must know about this replacement. ${ }^{29}$

There is no rule under the Red Book 2017 that deals with replacing the engineer's representative for reasons attributable to representative itself, as with those provided for under the last paragraph of Sub-clause 3.6 (death, illness, disability and resignation) which in effect means that the engineer has the sole authority and discretion to replace its representative once any of the above reasons takes place, without having to seek the contractor's consent.

To conclude, the authorities of the engineer are broader when compared to the related ones given to the contractor; that is to say, the engineer approves both late appointment and replacement of the contractor's representative, while the contractor can merely approve replacement of the engineer but not its representative. ${ }^{30}$ Furthermore, the contractor must give reasonable reasons for its objection to the new engineer, whereas the engineer is under no such a duty to justify its objection to the appointment or replacement of the contractor's representative.

Moreover, the engineer must consent to the appointment of the temporary contractor's representative when the original one becomes absent from the site. However, where the engineer wants to appoint a replacement of its representative in the site, a mere notification to the contractor suffices the purpose. In other words, the contractor consent is not required.

\section{Reflections on Qatari national law}

In this section, an attempt is made to reflect the most important issues discussed in the previous sections on Qatari national law. The underlying objective of such a reflection is to try to understand how FIDIC rules can be applied and implemented in Qatar in the light of the fact that FIDIC rules have no counterpart under the national law. Obviously, the national law here cannot be used here as a benchmark, or indeed as a ground for interpreting FIDIC, as both legal rules belong to different schools of legal theory.

No particular rules exist under the Qatari Civil Code (QCC) 2004 neither for the regulation of the work of the engineer nor for the definition of its authorities. QCC is concerned only with the contractual relationship between the employer and the contractor. ${ }^{31}$ The only direct mention to the engineer is made under Articles 711-715 regarding the so called decimal liability of the contractor and the engineer. ${ }^{32}$ Here, QCC provides that when the defects in the works are attributed to design only, the engineer is solely liable, but when such defects are found to be resulted from to the execution of works carried out under the supervision of the engineer, both the contractor and the engineer will be jointly liable. ${ }^{33}$

It is to be indicated here that the rules of decimal liability under QCC are of public order nature, which apply to any construction contract executed in Qatar, even if the contract is a FIDIC type. ${ }^{34}$

As for the legal position of the engineer under contract of works, QCC does not expressly determine whether the engineer is to be appointed by contractor, or employer, instead it impliedly indicates to the two scenarios. ${ }^{35}$ The relationship between the contractor or the employer on the one hand and the engineer on the other hand can be a mere employment one; however, the engineer can be independent working as a 
professional service provider. In the last scenario case, the legal relationship is more of a countering one whereby the engineer acts as an independent contractor who renders technical services. Finally, QCC envisages a third legal relationship, being agential one where the engineer works as a commercial agent for the benefit of the employer.

If an agency relationship between the engineer and the employer exists, then all rules earlier explained concerning the removal of the engineer may apply here and will be in line with the FIDIC rules. But, there are no requirements or procedures to seek any approval of any other party, particularly the contractor. ${ }^{36}$

However, in the most likely events where the Contract between the engineer and the employer is found to be a contract of works, then the engineer as a contractor is bound by the rules of the said contract, which setups the limits and boundaries for its duties and authorities. ${ }^{37}$ However, the employer cannot in this case remove the engineer by its sole decision, and without any reason. In other words, there should be a fault on the side of the engineer to invoke the right of the employer to remove the engineer. Obviously, this is due to the binding power of the contract as well-known under the general rules of law. ${ }^{38}$

To sum up, under QCC, the employer may appoint the engineer, and the contractor has no right to interfere in the relationship between the employer and the engineer, i.e., the contractor cannot object to the appointment of the engineer. Besides, the employer is not required to seek the contractor's approval for appointment or replacement of the engineer. This rule is based on the principle of privity of contract. ${ }^{39}$

Finally, FIDIC is widely known and used in Qatar, given the fact that huge construction projects are currently underway mainly in the preparation for Qatar hosting the World Cup 2022. ${ }^{40}$ These projects are normally awarded to international construction companies and consulting engineers who are well acquainted with FIDIC. As FIDIC rules are likely to govern such contracts, their application seems spur so many legal concern due to the fact that they are different or vary to a great extent from the rules of national law.

\section{Conclusions}

The new 2017 Red Book edition adds some new rules with regards to replacement of the engineer, one of which is that the contractor is given 14 days to object to such replacement, after which time he is deemed to have approved the replacement. It also confirms that engineer does not always work for employer as an agent; here, Sub-clause 3.7 expressly provides that the engineer is not an agent in cases of 'agreement' and 'determination'.

The mere right of the contractor to object to the replacement of the engineer embodies a departure from the golden rule of privity of contract, since the contractor is not party to the contract between the employer and the engineer. However, it is argued that this approval, even when so required, does not amount to be a consent, since the contractor is contractually required to provide rationale for its disapproval. Otherwise, the employer becomes entitled to challenge the contractor disapproval. Clearly, the interest of the project justifies the said requirement.

However, while the replacement that takes place at the middle of execution of work justifies the necessity for having the contractor's approval, the appointment by the employer of the engineer in the first place does not require the contractor's approval, as 
this is the sole right and discretion of the employer to contract with whoever engineer it may see fit.

The 2017 Red Book has introduced other new rules relating to the replacement of the engineer; namely replacement for reason attributable to the engineer (death, illness, disability and resignation). Basically, these are emergency cases, which necessitate different procedures to be followed by the employer; hence a temporary engineer must be appointed to start work immediately, the contractor's approval will be sought. If the contractor withholds its approval, the employer must then nominate another engineer. The underlying objection here is to avoid any gap in execution of the work.

It is noticed that the engineer enjoys broader authorities in the context of dealing with the contractor. For example, while the engineer has to approve the appointment and/or replacement of the contractor's representative, the engineer enjoys a full discretion of appointing and/or replacing its own representative. The only case where the engineer must here refer to the contractor, is where the said representative is absent from site, then the engineer must send to the contractor a mere notification of replacement for information only.

It has been found that FIDIC rules are far from the relevant rules of national laws. For example, under the QCC 2004, the engineer can be appointed by the contractor, or the employer. In other words, there is no counterpart under the national law to most rules that exist under the FIDIC. Yet, this is by no means a reason to call for avoiding the use of the FIDIC rules. Rather, we should always avoid considering national laws as benchmark, or yardstick in our attempts to understand, interpret and apply FIDIC rules.

As a general rule, the terms of FIDIC Red Book shall supersede the provisions of QCC, to the extent that such terms do not contradict with any mandatory legal rules provided for under QCC. It can be well concluded here that the entire FIDIC Red Book rules, which deal with the position of the engineer do not touch public order rules under QCC, except the rules concerning decimal liability. Hence, QCC decimal liability rules shall always apply to any FIDIC-based contract.

\section{Notes}

1 See Sub-clause 3.1 of the new FIDIC Red Book, which provides "the employer shall appoint the engineer, who shall carry out the duties assigned to the engineer in the contract." Sub-clause 1.1.35 defines engineer as "means the person named in the contract data appointed by the employer to act as the engineer for the purposes of the contract, or any replacement appointed under Sub-clause 3.6 \{replacement of the engineer\}."

2 It is worth noting that the version of Red Book before 1999 did not provide for replacement of the engineer. The version of 1999 first regulated this issue. See Bateson, D. (2000) FIDIC New 1999 Edition of the Red Book, Impartiality of the Engineer [online] http://fidic.org/sites/ default/files/9\%20FIDIC\%20-\%20New\%201999\%20Edition\%20of\%20the\%20Red\%20Book. pdf (accessed October 2018). It is submitted that allowing the employer to replace the engineer gives flexibility, since the employer needs to change his staff, without harming the contractor, who keeps the right to reasonably object the replacement. Otherwise, the employer will be bound by the same engineer for the whole life of the project, which constitutes a harsh and rigid rule. See Kolonne, T.P. (2012) 'Engineer', in FIDIC Red Book(s) [online] http://www.slqsuae.org/wp-content/uploads/2014/12/Article33.pdf (accessed October 2018).

3 The new FIDIC identifies the employer's personnel in Sub-clause 1.1.33 as "means the engineer, the engineer's representative (if appointed), the assistants described in Sub-clause 3.4 \{delegation by the engineer\} and all other staff, labour and other employees of the engineer and of the employer engaged in fulfilling the employer's obligations under the 
contract; and any other personnel identified as employer's personnel, by a notice from the employer or the engineer to the contractor".

4 See Tyson, V. (2017) The Employer's Agent [online] http://corbett.co.uk/the-employers-agent/ (accessed October 2018). See also Lina, C. (1997) 'Role of engineer under FIDIC form contract', Journal of Professional Issues in Engineering and Practice, Vol. 123, No. 2, p.48.

5 See Sub-clause 3.2 of 2017 Red Book, and Sub-clause 3.1 of the 1999 FIDIC.

6 The engineer is not considered an agent in case of determinations, under Sub-clause 3.7. See Corbett, E. (2017) FIDIC 2017 - First Impressions of the 3-Kilo Suite [online] http://corbett. co.uk/2017/12/?cat=11 (accessed October 2018). See also FIDIC Updates to Impact Engineers and MidEast's Project Employers, 17 February 2018, Dubai, ConstructionWeekOnline. com [online] https://0-search.proquest.com.mylibrary.qu.edu.qa/docview/2002607668/fulltext/ B92A66607E1B457CPQ/5?accountid=13370 (accessed October 2018).

7 See Sub-clause 3.7 of the 2017 FIDIC which provides "when carrying out his/her duties under this subsection, the engineer shall act neutrally between the parties and shall not be deemed to act for the employer." The dual role of the engineer has been a subject of criticism and debate since the emergence of different editions of FIDIC, it is established that the engineer is employed and paid by the employer, notwithstanding, he must be impartial or fair and finally in the 2017 version neutral. See No. 4 above [Lina, (1997), p.49]. See also No. 4 above (Tyson, 2017).

8 See Sub-clause 3.5 of the 1999 version which stated “... the engineer shall make a fair determination."

9 See Sub-clause 3.7 which provides "When carrying out his/her duties under this sub-clause, the engineer shall act neutrally between the parties and shall not be deemed to act for the employer."

10 See Sub-clause 3.2 of the new FIDIC Red Book 2017. It is submitted that the appointment agreement specifies normally the duties of the engineer, it also restricts, or withdraws some of his authorities. See NBM \& CW: New Building Materials \& Construction World (2014) 'Position of engineer \& independent engineer in standard forms of contracts', 6 June, New Delhi [online] https://www.google.com/search?q=“+Position+of+Engineer+\%26+ Independent+Engineer+In+Standard+Fo (accessed October 2018).

11 Müller-Freienfels, W. (2018) Agency Law, 13 April [online] https://www.britannica.com/ topic/agency-law (accessed October 2018).

12 See Sub-clause 3.4 of the FIDIC Red Book 1999. It became Sub-clause 3.6 of the new FIDIC 2017.

13 Privity of contract means, that the effect of the contract must not extend and touch a third person who is not a party to the contract. Besides, those non-parties to a contract must not interfere in the execution of it. Privity of contract is defined in Black Law Dictionary, "The relationship between the parties to a contract, allowing them to sue each other but preventing a third party from doing so." See also Poole, J. (2016) Casebook on Contract Law, Oxford University Press, Oxford [online] http://www.oxfordlawtrove.com/ view/10.1093/he/9780198732815.001.0001/he-9780198732815-chapter-11 (accessed October 2018).

14 The parties may use Clause 21 of the FIDIC Red Book 2017, which sets rules for settling disputes through DAAB.

15 The criterion of reasonableness is objective one, the DAAB decides in the light of the circumstances whether the reasons given by the contractor, by which he objects the replacement of the engineer meet the criterion of reasonableness. Examples for that might be lack of experience in the side of the engineer in the related project.

16 See Sub-clause 3.6 of the 2017 Red Book.

17 Simran, CNLU, Patna, Termination of Agency Under Contract Act [online] https://www.lawctopus.com/academike/termination-of-agency-under-contract-act/ (accessed October 2018).

18 See No. 13 above. 
19 See No. 17 above.

20 According to the first paragraph of Sub-clause 3.6, the employer must send a notice to the contractor before 42 days of the intended date of replacement, and the contractor has 14 days to respond.

21 See Sub-clause 3.6 which provides "----the employer shall, not less than 42 days before the intended date of replacement, give a notice to the contractor-----."

22 Knutson, R. (2003) An English Lawyer's View of the New FIDIC Rainbow - Where is the Pot of Gold? [online] https://nanopdf.com/download/knutsonrainbow_pdf (accessed October 2018).

23 Sub-clause 3.5 of the new Red Book provides ".....the contractor shall comply with the instructions given by the engineer or the engineer's representative (if appointed) or delegated assistant, on any matter related to the contract."

24 According to Sub-clause 3.5 the contractor may consider an instruction a variation order, or part of an existing variation, or does not comply with applicable laws or will reduce the safety of the works or is technically impossible. In which a case the contractor must send a notice to the engineer, with reasons, the engineer will have seven days to respond confirming, reversing or varying the instruction, if he does not respond, he shall deemed to have revoked the instruction. But if he responds, the contractor is obliged by the instruction, as the terms of the engineer's response.

25 See No. 2 above Kolonne (2012).

26 Sub-clause 1.1.18 of the 2017 FIDIC defines contractor's representative as "means the natural person named by the contractor or appointed by the contractor under Sub-clause 4.3 \{contractor's representative\}, who acts on behalf of the contractor." Moreover, Sub-clause 1.1.17 of the 2017 FIDIC defines the contractor's personnel as "means the contractor's representative and all personnel whom the contractor utilizes on sit or other places where the works are being carried out, including the staff, labour and other employees of the contractor and of each subcontractor; and any other personnel assisting the contractor in the execution of the works."

27 See Sub-clause 4.3 of the FIDIC Red Book 2017

28 Engineer representative is defined under Sub-clause 1.1 .36 of the 2017 version as 'means the natural person who may be appointed by the engineer under Sub-clause 3.3 \{engineer's representative\}'.

The engineer may delegate all his duties to his representative, except agreement or determination, besides issue of notice to correct. See Sub-clause 3.4. It is argued that the engineer's representative should have the authority of agreement and determination, to distinguish his role from that of the assistants. See No. 11 above, FIDIC updates to impact engineers and MidEast's project employers.

29 The fourth edition of the FIDIC did recognise a similar rule, the 1999 version did not provide for engineer's representative, however, the FIDIC 2017 reintroduced these rules. See Tyson, V. (2018) Clause 3: The Engineer, Corbett \& Co, International Construction Lawyers [online] https://corbett.co.uk/clause-3-the-engineer/ (accessed October 2018).

30 It is worth noting that according to Sub-clause 4.3 “.....if the engineer does not respond within 28 days after receiving this submission, by giving a notice to the contractor objecting to proposed person or replacement, the engineer shall be deemed to have given his/her consent."

31 Works contract is regulated under the QCC No. 22 for the year 2004 articles (pp.682-715).

32 According to Article 711 of the QCC, in a contract for works, the design of which is made by the engineer, and the execution of work is under his supervision, both of the engineer and the contractor shall be liable to compensate the employer for whatever happens during ten years from the total or partial demolition of the buildings they have constructed, or the construction they have built and for every defect which threatens the stricture, strength and the safety of the building. 
Liability for the said compensations shall subsist even if the defect or demolition results from a defect in the land itself or the employer's consent to the building of the defected constructions. The period of the ten years shall commence on the date of the taking over of the work.

33 According to Article 712 of the QCC, if the engineer's work is limited to the making of design without supervision of execution, he shall only be liable for the defects of design, and if the contractor shall work under the supervision of an engineer, he (engineer) shall be liable for the defects in execution of the work.

According to Article 715 of the QCC, any condition intended to exempt from or limit the contractor's or engineer's liability shall be void.

34 Adapting FIDIC Provisions for Use in Qatar [online] https://www.out-law.com/en/topics/ projects--construction/construction-standard-form-contracts/adapting-fidic-provisions-for-usein-qatar/ (accessed October 2018).

35 See Article 712/2 of QCC "Where the employer assigns the engineer to supervise the execution in whole or in part, such engineer shall also be liable for such defects that may arise from the method of execution supervised by him." And Article 713/2, "However, the contractor shall be liable for defects arising from the design if the engineer who prepared the design is employed by the contractor."

36 According to Article 735 of the QCC, the principal may terminate the agency or restrict it, by his sole discretion. However, the principal is liable for the damage caused to the agent by his termination at an improper time or for no acceptable justification. Article 736 provides for the agent's right to remove himself from the agency by a notice addressed to the principal, however, the agent is liable for the damage caused to the principal by his termination at an improper time or for no acceptable justification.

37 See Article 687 of the QCC, which provide for the contractor's duty to perform the contract according to its terms and conditions, and within the timeframe agreed upon, taking into consideration the nature of the work and the industry practice.

38 According to Article 171 of the QCC, the contract is binding to its parties, it shall not be terminated or amended, except by the consent of both parties, or under the cases decided by law.

39 According to Article 175 of the QCC, the effect of the contract shall attach to the two contracting parties and the general successors, without prejudice to the rules of succession, unless it is ascertained from the contract, the nature of the transaction, or the provisions of the law that the said effect shall not attach to the general successors.

40 The Cost of the World Cup Construction Work in Qatar is Estimated to be $\$ 200$ Billion [online] http://meconstructionnews.com/23672/western-contractors-in-qatar-draw-upcontingency-plans-for-exit (accessed October 2018). 